Fernando Durán V.

\title{
Menéndez y Pelayo y la critica
}

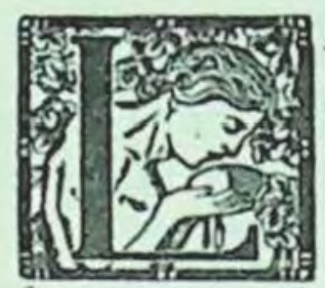

A obra de arte tiene una doble existencia, pues se vierte en dos sentidos o direcciones. De una parte, yace en sí misma, lanzada en medio de la comunidad humana y como cerrada sobre su propio ser, constreñida por la forma que la individualiza. Pero, además, existe en los seres humanos que la contemplan y que, bajo ese aspecto, se la interiorizan y hacen suya. Más radicalmente aún, cabe decir que toda obra de arte es en su esencia una intención que en forma constitutiva, y por el sólo hecho de darse la estructura que posee, se dirige ya con carácter consubstancial a alguien que la contemple y la aprecie.

Dada la existencia doble de la obra artística, es evidente que ésta nace por y para ser comunicada, de manera que en su razón intrínseca de ser encontramos ya su predestinación a ser recibida y acogida por un virtual contemplador. En el diálogo fundamental en que consiste toda vida, y donde dialogan el yo y la realidad que lo circunda, el punto más alto en la esfera humana es, sin duda, el de la comunicación artística, que supone la participación en un orden ideal y trascendente, por lo tanto, a la desnuda y limitada realidad.

Todo lo anterior nos conduce a la conclusión de que la obra de arte es esencialmente una apertura sobre el mundo, que se opera 
bajo una doble vía. De un lado, en ella se abre y se vuelca el creador, esto es, quien la intuye, la ordena y la expresa o hace salir de su interioridad. Del otro, también se abre el que la contempla o considera, porque él también siente repercutir en su alma las vivencias extrañas que, como un llamado, resuenan en él y lo incorporan a la experiencia sintetizada por el artista en la creación que le ofrece.

De allí que la crítica de arte sea algo esencial e indispensable dentro de la vida artística, debiendo decirse igual cosa de la crítica literaria respecto de las creaciones de este orden. La sola existencia de una creación literaria genera por sí sola la aparición de un crítico en esbozo, que es cada uno de sus lectores. Esta apreciación o valorización de la obra, como ha señalado Albert Thibaudet, comprende diversas categorías o etapas. La más elemental y modesta es la que dicho autor denomina como espontánea, y que consiste en la apreciación inmediata que efectúa todo el que lee, al comprobar que la obra le gusta o desagrada, le entusiasma o le fastidia. Pero, elevándonos en la escala de estas estimaciones, rápidamente nos encontramos con otro tipo de crítica que podríamos llamar reflexiva y artística. Esta es la que practican los que, organizadamente y en forma deliberada y sabia, se consagran al examen de los engendros literarios y se proponen juzgarlos y valorizarlos.

En la ingente y caudalosa obra de don Marcelino Menéndez y Pelayo, encontramos, sin mayor búsqueda, que el aspecto crítico ocupa una parte considerable de la misma. El maestro cuya excepcional faena recuerda en estos días el mundo entero, asombra al que la examina por la magnitud de sus dimensiones y por la hondura y vastedad que a su tamaño se unen. Como se ha dicho muchas veces, el extraordinario polígrafo sorprende por la cantidad y la calidad de su labor, uniendo, en una síntesis que rara vez se produce, la extensión a la intensidad. Marchan, así, a la par la curiosidad inagotable y el orden sistemático, la voracidad por conocerlo y averiguarlo todo y el afán riguroso de hacer caber este resultado dentro de un método claro y constructivo. 
La primera nota que descubrimos en este afán de omnisciencia, de penetración en todos los campos y extensiones del saber humano, es ła de la universalidad de Menéndez y Pelayo. No se trata aquí, y bien lo demuestran sus trabajos, de una curiosidad desordenada y dispersa, que corre de un punto a otro por incapacidad de fijar la atención en uno determinado. Por el contrario, el deseo de un saber siempre creciente, de una ciencia que mientras más se avanza en ella más hace retroceder sus límites, responde a una profunda voluntad de humanidad. En tal sentido, y la comparación ha sido hecha fecundamente por Pedro Lain Entralgo, Menéndez y Pelayo denota en este aspecto primero de su contacto con nosotros que no quiere ser un hombre de reducciones o mezquindades, sino un intelectual de moderna estirpe, a quien todos los aspectos de la experiencia humana, entendiendo por tal tanto la vivida cotidianamente como la percibida a través del espíritu, entren a integrar la esfera de sus conocimientos.

Más adelante veremos otras calidades de esta intención y afán universales de Menéndez y Pelayo, pero por ahora convendrá añadir que en ellos palpita el propósito de un mayor ahondamiento en el ser humano, de una decisión de encontrar aquello que con frase de Max Scheler podríamos llamar "lo eterno en el hombre", a fuerza de hundir más gravemente la mirada en las numerosas expresiones que de este universal ofrecen las singularidades con que el individuo se presenta en sus distintas fisonomías.

Ya lo dicho nos obliga a subrayar otro aspecto de su labor. Menéndez y Pelayo tuvo una categórica conciencia de que la obra literaria no es un ente aislado, que yazga al margen de la serie de circunstancias y supuestos que la explican y en cierto modo la producen. Esa obra nace dentro de un tiempo histórico determinado, de una atmósfera social, psicológica e incluso material, de los cuales no puede ser aislado so pena de que nos neguemos la posibilidad de entenderla. En otras palabras, en el libro, ya sea poesía, novela, historia o ensayo filosófico, convergen una enorme masa de elementos 
que éste recoge y expresa y sin cuya asistencia no es posible darle el verdadero sentido que posee y se propuso manifestar.

La incursión minuciosa y prolija del polígrafo en la montaña de documentos que expurgó y compiló para desarrollar su obra, no está animada de un mero afán erudito. Al contrario, la erudición es como una mera sierva de otra finalidad y se circunscribe a situar la obra en un campo determinado, a reconstituir la época en que ella tuvo origen, a reanimar el cuadro histórico en que vivieron el autor y sus contemporáneos y, en fin, a determinar las influencias que hacia esa obra convergieron y las que, a su vez, ella tuvo en las otras creaciones en que repercutió.

Esto nos hace ver claro que el erudito es en este caso un simple y previo colaborador del artista que más tarde se apoderará de todos esos materiales, los iluminará con su vigorosa intuición estética y les conferirá, mediante esta verdadera sublimación que en ellos efectúa, el rango de una nueva creación literaria. Es precisamente en este punto donde el artista que había en Menéndez y Pelayo demuestra su vigoroso poder y logra hacer de la crítica una interpretación, esto es, un modo nuevo y distinto de creación, en tal forma unido a la obra que vienen a ser como el eco y la voz, como el espejo y el rostro que en él se refleja.

Resulta imposible ubicar la obra literaria del polígrafo sin reconocerle, por lo ya dicho, una dimensión histórica fundamental. Baste decir que en su abrumadora erudición, caben las literaturas heleno-románicas y todas las europeas posteriores, en cuyas fuentes se interioriza con destreza y energía inagotables. Todo lo lee y devora este hombre, a quien con justicia ha llamado Dámaso Alonso "simún de lectores" y "Sahara de polígrafos", porque sólo un vendaval podría haber arrastrado semejante caudal de lecturas y únicamente un desierto inmenso ofrecería extensión suficiente para compararla con la vastedad de sus labores y conocimientos.

Su criterio histórico, mejor dicho, su sensibilidad para deslizarse en el interior del pasado, lo hace anticiparse, como muchos lo subrayan ya, a las intuiciones del moderno historicismo. Preludiando, aun- 
que todavía en términos no suficientemente explícitos, la posición de Menéndez y Pelayo se enlaza con la de un Dilthey y hasta la de un Ortega y Gasset, en cuanto vincula íntimamente la fidelidad al dato con la inserción y vitalización de éste en el tiempo singular a que corresponde.

"Para comprender el alma de un pensador - sostiene- es necesario pensar con él, reconstruir idealmente el proceso dialéctico que él siguió, someterse a su especial tecnicismo y no traducirle bárbara e infielmente en una lengua filosófica que no es la que él empleó. Y se necesita, además, colocarle en su propio medio, en su ambiente histórico, porque la especulación racional no debe aislarse de los demás modos de la vida del espíritu, sino que con todos ellos se enlaza mediante una complicada red de sutiles relaciones que al análisis crítico toca discernir. De donde se infiere que el genio filosófico de un pueblo o de una raza no ha de buscarse sólo en sus filósofos de profesión, sino en el sentido de su arte, en la dirección de su historia, en los símbolos y fórmulas jurídicas, en la sabiduría tradicional de sus proverbios, en el concepto de la vida que se desprende de las espontáneas manifestaciones del alma popular”.

Cambiemos la palabra pensador por artista o literato, y tendremos señalado por la propia mano del investigador el enfoque que él hace de la obra creada, ubicándola en una temporalidad sin la cual se hace ininteligible.

Sin embargo, no acabaríamos de entender al escritor si no señaláramos al mismo tiempo que este historicismo o deslizamiento en el pasado revivido, debe hacerse mediante dos procedimientos: el primero, rememorándolo desde un ángulo vital, es decir, con una inclinación intencional, especie de desdoblamiento psicológico por el cual nos transportamos al pasado y lo convertimos en presente; el segundo, deslizando en este pasado así rescatado un elemento de reconstitución artística, sin el cual los elementos que lo constituyen no pueden adquirir unidad ni ensamblarse ágilmente en una síntesis conquistadora y animada. 
Leyendo una y otra vez su discurso sobre la historia considerada como obra artística, hallamos la confirmación de sus conceptos sobre la historia y sobre el arte. En cuanto a aquélla, distingue desde luego la materia y el contenido de una parte, y la forma, tomada en un sentido interior e inmanente a la creación, en la otra. "De la historia vengo a hablaros, dice; pero no considerada en su materia y contenido, ni siquiera en las reglas críticas y método de investigación para escribirla, sino de lo que a primera vista parece más externo y accidental en ella, de lo que condenan muchos desdeñosamente con el nombre de forma; como si la forma fuese mera exornación retórica y no el espíritu y el alma misma de la historia, que convierte la materia bruta de los hechos y la selva confusa y enorme de los documentos y de las indagaciones, en algo real, ordenado y vivo, que merezca ocupar la mente humana, nunca satisfecha con vacías curiosidades, y anhelosa siempre por las escondidas aguas de lo necesario y eterno". "Voy a hablar, continúa, pues, no de crítica histórica propiamente dicha, sino de la historia considerada como arte bella, de la noción estética de la historia; ya que es grave defecto en los modernos tratadistas excluir del cuadro de las artes secundarias, el arte maravilloso de los Tucídides, Tácito y Maquiavelo, mientras que admiten sin reparo y explanan en muchas páginas el arte de la danza o el de los jardines. No es, en verdad, la historia obra puramente artística, como lo son la poesía, o la música, o las creaciones plásticas; pero son tantos y tales los elementos estéticos que contiene y admite, que obligan a mi entender, a ponerla en jerarquía superior a la misma oratoria, encadenada casi siempre por un fin útil e inmediato, extraño a la finalidad del arte libre, que en la misma hermosura que engendra se termina y perfecciona, deleitándose con ella"..

Tomando en seguida pie de un texto de Aristóteles, que estaría según algunos mal interpretado, llega a una conclusión que, no obstante, es de gran importancia y constituye una de sus más felices intuiciones. Para Menéndez y Pelayo, el poeta y el historiador no se distinguen en cuanto a la materia sobre la cual trabajan, porque am- 
bos actúan sobre la realidad. No existe en ellos creación propiamente dicha, porque tanto uno como otro parten de la naturaleza humana y se fundamentan en ella, no siendo, por lo tanto, dueños de su material. Es éste el que se les impone y les dicta su estructura. Pero el poeta desprende de esa realidad concreta que tiene al frente, una verdad ideal, esto es, el fondo de universalidad que ella encierra. El historiador se eleva a la categoría de tal, cuando conjetura, a base de los datos del pasado, las acciones realizadas por los hombres a quienes está historiando, en otras palabras, cuando apoyándose en dichas acciones penetra en las razones por las cuales hicieron lo que hicieron, eligiendo entre todo el repertorio de actos posibles precisamente aquellos que ejecutaron.

La audacia de la afirmación de Menéndez y Pelayo no puede ser más categórica y desafiante. Parece imposible que un crítico e investigador, que escribe en pleno auge y floración del positivismo más extremo, bajo las sombras tutelares de Taine y en una atmósfera literaria naturalista, dispuesta a reducir la novela a una mera experimentación, haga la declaración siguiente: "La vida humana es un drama, y el historiador aspira a reproducirla. Puede ser crítico, puede ser erudito, mientras reune los materiales de la historia y pesa los testimonios e interroga los documentos; pero llegado a escribirla, no es más que artista, y no tanto quiere dar lecciones, aunque lo anuncie en fastuosos premios, como reproducir formas y colores, y aún más que estos accidentes, externos o pintorescos de la vida, la vida moral que palpita en el fondo. De aquí bellezas puramente dramáticas; de aquí el análisis de los caracteres; de aquí la necesidad de los retratos, de las epístolas y de los discursos. No le basta al historiador clásico que los personajes hablen con la voz de sus hechos; no le basta presentarlos vivos y en acción; quiere trasladar al papel lo más recóndito de su conciencia y mostrarnos el laboratorio de los misterios psicológicos... Así se funden armoniosamente ciencia y arte. El historiador se lanza al mundo poético de lo verosímil en alas de lo verdadero. En las narraciones no refiere, sino que pinta. No explica los motivos de las acciones, hace que los mismos persona- 
jes nos los refieran..." Idea que párrafos más adelante se completa con la siguiente: "De todo lo cual infiero yo que la historia clásica es grande, bella e interesante, no por lo que los retóricos dicen, sino por todo lo contrario; no porque el historiador sea imparcial, sino, al revés, por su parcialidad manifiesta; no porque le sean indiferentes las personas, sino, al contrario, porque se enamora de unas y aborrece de muerte a otras, comunicando al que lee, este amor y este odio... no porque abarque mucho y pese desinteresadamente la verdad, sino porque abarca poco y descubre sólo algunos aspectos de la vida, encarnizándose en ellos con fruición artística; no porque sirva de grande enseñanza a reyes, príncipes y capitanes de ejército, dándoles lecciones de policía, buen gobierno y estrategia, sino porque ha creado figuras tan ideales y serenas como las de la escultura antigua, y otras tan animadas y complejas como las del drama moderno; no porque enseñe a "bien vivir", como dijo Luis Cabrera, a pesar de los aforismos con que solían engalanarla, sino porque produjo en Tácito el más grande de los artífices creadores de hombres, si se exceptúa a Shakespeare".

El giro hiperbólico que adopta Menéndez y Pelayo al hacer estas afirmaciones, señala con vigor su actitud estética. En una graduación clara y bien perceptible, el polígrafo parte de los datos y documentos, los hace cruzar por los pasillos de la inteligencia, la cual los ordena, depura y armoniza, pero es la sensibilidad estética, lo que podríamos llamar acaso la "imaginación creadora", la que transforma todos estos materiales y, de antecedentes inconexos y muertos que eran, los alza de un golpe a la cumbre de la creación artística.

Al hacer esta bella apología de la sensibilidad estética Menéndez y Pelayo anticipa otra noción que la moderna crítica artística ha difundido. Para él la ciencia es el punto de partida de la obra histórica y el arte su punto de llegada, pero el tránsito de lo inteligido o conocido a lo creado estéticamente no se da sino mediante la intervención de la sensibilidad o del amor, como él prefiere decir. Esto es, la penetración en lo pasado, el deslizamiento, que mencionábamos, en tiempos idos, sólo se obtiene por vía de lo que hoy la estética 
llama la "vivencia", o sea, el cinfuhlung del léxico alemán. Por eso se siente impelido a rubricar que "para enseñorearse del reino de lo pasado, para lograr aquella segunda vista que pocos mortales alcanzan, es preciso que la inteligencia pida al amor sus alas, porque, como dijo profundamente Carlyle, para conocer de veras una cosa, hay que amarla antes, hay que simpatizar con ella".

No se crea por esto que el investigador siente inclinaciones por las corrientes irracionalistas de la filosofía o por algún vitalismo estético que desconfíe de la razón y trate de desterrarla. Por el contrario, para su visión eminentemente humanística, el hombre es un ente racional, pero esa razón, como dirían hoy los orteguianos, no es una entidad abstracta, intemporal y desencarnada, sino que se da en un hombre concreto, singular, que vive aquí y ahora, en este tiempo y en este lugar. La razón ilumina, apunta hacia la esencia de la realidad, hacia lo que ésta tiene de universal, pero es la sensibilidad la que se une con lo que el individuo tiene de único e intransferible, y, por lo tanto, es capaz de interiorizarse en él y de hacerse otro idéntico a él.

\section{II}

Hemos visto la importancia substantiva que en la labor crítica de Menéndez y Pelayo tiene el artista. Señalemos algunos puntos de vista, ahora, sobre su comprensión de las obras literarias y sobre la estética que al respecto se desprende de sus interpretaciones.

El polígrafo santanderino vivió en una época difícil y extraña a sus tendencias filosóficas e intelectuales. Pensémoslo nacido en las postrimerías del romanticismo, hacia 1856, y escribiendo sus obras más decisivas en un medio inficionado de positivismo y naturalismo, en un sector, y de vagas e indefinidas filosofías, de notoria desviación panteística, en otros. El era y se confesaba un clásico, y basta leer lo que ha escrito sobre el Renacimiento para comprender que estamos en presencia de un intelectual del siglo XVI por el espíritu, a quien 
ahogan tanto las sórdidas limitaciones positivistas como las confusas y anodinas formulaciones del krausismo.

En esta actitud intelectual suya encontraremos la explicación de sus atisbos sorprendentes, así como de sus incomprensiones, igualmente desconcertantes, frente a la gran poesía barroca, en especial Góngora y, en mucha medida, el propio Calderón.

Para un hombre de la estirpe y de la cultura de Menéndez y Pelayo, el naturalismo, expresión literaria del positivismo, debía ser algo insoportable y odioso. No se trataba de una intolerancia gazmoña, que se escandalizara ante ciertas crudezas de la novela "experimental", sino de la crispación instintiva del verdadero artista ante la subordinación del arte a consignas o prejuicios que lo desnaturalizaban y prostituían en su misma fuente.

Analizando la obra de Pereda, se ve obligado a entrar a definir su posición frente al naturalismo. La página que entonces escribe, explaya sus ideas estéticas y define serenamente, y con honda filosofía, sus discrepancias ante esta tendencia. "El que recorra atentamente esos libros de Zola, afirma refiriéndose a Le Roman experimental y Les romanciers naturalistes, advertirá sin duda cuán vagas y confusas nociones tiene el autor de lo que debe entenderse por verdad humana y qué concepción tan torcida del arte es la que se ha formado. Entendidos ambos conceptos en el sentido groserísimo en que él los entiende, ni sus novelas, ni otras algunas, tendrían razón de existir. En la misma noción del arte va envuelta la del ideal, siendo la una inseparable de la otra. El mismo Zola llega a reconocerlo así, aunque con una frase de crudo materialismo, cuando declara que el arte no viene a ser otra cosa que la naturaleza vista a través del temperamento de un artista, es decir, modificada por eso que Zola llama temperamento. Pues bien, esa modificación que el artista más apegado a lo real impone a los objetos exteriores, por medio de los dos procedimientos que llamaré de intensidad y de expresión, arranca de la realidad material esos objetos, y les imprime el sello de otra realidad más alta, de otra verdad más profunda; en una palabra: los vuelve a crear, los idealiza. De donde se deduce que 
el idealismo es tan racional, tan real, tan lógico y tan indestructible como el realismo, puesto que uno y otro van encerrados en el concepto de la forma artística, la cual no es otra cosa que una interpretación (ideal como toda interpretación) de la verdad oculta bajo las formas reales. Merced a esta verdad interior, que el arte extrae y quintaesencia, todos los elementos de la realidad se transforman, como tocados por una vara mágica, y hasta los personajes que en la vida real parecerían más insignificantes, se engrandecen al pasar al arte, y por la concentración de sus rasgos esenciales, adquieren valor de tipos (que es como adquirir carta de nobleza dentro de la república de las letras), y sin dejar de ser individuos, rara vez dejan de tener algo de simbólico. Y es que los ojos del artista en algo han de distinguirse de los del hombre vulgar, y su distinción consiste en ver, como entre sombras y figuras, lo mismo que el filósofo alcanza por procedimientos discursivos, es decir, la médula de las cosas, y lo más esencial y recóndito de ellas. De donde procede que los grandes personajes creados por el arte (que, a su manera, es creación) tienen una vida mucho más palpitante y densa que la mayor parte de los seres pálidos y borrosos que vemos por el mundo". Párrafos más allá, contraponiendo el personaje literario al ente real y cotidiano, tiene una afirmación que no habría desdeñado Pirandello. “... No reparan que si en el mundo no hay Amadises, tampoco hay Gargantúas ni Pantagrueles, porque las caricaturas gigantescas no son más que idealizaciones sui generis, siendo bajo este aspecto tan ideal un sueño de Quevedo como una tragedia de Esquilo o unos tercetos de Dante. A nadie se le persuadirá que don Francisco de Quevedo, que era en prosa y en verso un poeta lírico antes que todo, idealizador de lo feo, como quien miraba la miseria con vidrio de aumento, hizo la figura de ningún avaro real ni posible en su Licenciado Cabra. El Euclión de Plauto o el Harpagón, de Moliére, tipos abstractos, creados para demostrar una máxima ética, están con todo eso, más cerca de la vida que el personaje quevedesco, lo cual no quita nada a la excelencia de este último, antes, a mi entender, la aumenta". La frase es sintomática: el que el personaje de Quevedo no esté 
tan cerca de la vida como los de Plauto o Moliére, no le resta excelencia sino que se la aumenta. En otros términos, está aquí claramente destacada la oposición entre realidad y arte, entre naturaleza y creación artística, quedando del lado de los últimos las mejores calidades.

La razón no es difícil de percibir, porque ya nos la ha dicho antes al referirse al naturalismo, con ocasión de las novelas de Pereda. Ningún artista, en la misma medida en que lo es, copia la realidad o se limita pasivamente a repetirla. Por el contrario, lo que hace es apoderarse de ella, interiorizársela, elevarla a una segunda realidad espiritual. Entonces, cuando ya la ha hecho suya y la posee hasta su raíz más esencial, el espíritu la universaliza, desprende de ella lo que tiene de ideal. Es, por consiguiente, la forma, penetración del alma en la cosa creada, ademán por el cual se apodera de ésta y le imprime su sello, el rasgo definitivo del arte. Podríamos repetir ahora la célebre frase del pintor renacentista: la pintura es cosa mental, pinto una certa idea que mi vien in mente. Pero esta idea se mide y se modela sobre la cosa, para trascenderla y sobrepasarla, devolviéndonos esa cosa más su eco en el alma. No es menos lo que llamamos la re-creación, o vuelta a crear de las realidades en el alma del artista.

Con los antecedentes que hemos agrupado, ya podemos formarnos un concepto de lo que Menéndez y Pelayo pide a la creación literaria, esto es, del punto de vista en que se coloca para juzgarla.

En unos apuntes que tomó cuando daba sus exámenes de oposición para la cátedra en la Universidad, a los 22 años, consigna ya precozmente su programa de maestro y también sus conceptos sobre la crítica. Distingue en ellos entre la crítica histórica y la estética y señala que en orden a la literatura es preciso aplicar las dos. El acto por el cual se percibe la belleza es mixto, o sea, participan en él la inteligencia y el sentimiento, cuya intervención se traduce en un juicio y una emoción. El crítico, señala, debe tener si no facultades artísticas, al menos análogas a las artísticas, y tiene que penetrar en la génesis de la obra "y ponerse hasta cierto punto en la situación 
del autor analizado". "Puede faltar al crítico, añade, el talento de ejecución, pero en manera alguna las otras condiciones". Otra vez insiste en la primacía del artista sobre el hombre meramente inteligente, porque la comprensión estética lo abarca todo, es decir, involucra una enajenación del contemplador en la cosa contemplada.

Hemos visto que Menéndez y Pelayo insiste mucho, ante el naturalismo, en un arte idealista. Entendámonos sobre qué él llama o denomina idealismo. Ya dijimos antes que repugnaban a su claridad renacentista las confusiones del krausismo que, no obstante el valor circunstancial que para determinada generación española pueda haber tenido en cuanto contacto con otro pensamiento europeo, debía aparecer incompatible para el pensador con una auténtica y sólida filosofía. En efecto, él era un amante de la claridad, no en cuanto una facilidad que allanara el camino, sino en cuanto al orden y nitidez de las ideas, al engarce de éstas con la realidad sobre la cual caen y a la que constantemente aluden.

Pero era sí un idealista en el sentido platónico, esto es, como convencido de que en todo ser existente hay dos elementos que lo integran: uno, su concreción inmediata y singular; otro, un universal que dentro de él se encierra y se individualiza. Cada hombre es, a la vez, este hombre pero lleva implícita además la humanidad. Entender un fenómeno estético, descubrir la belleza de una cosa es justamente captar y recoger el resplandor que sobre ella proyecta algo que no es la cosa misma, mostrenca, constreñida dentro de su inmediato límite.

El platonismo con reminiscencias agustinianas, que se percibe en Menéndez y Pelayo, otorga al mundo una triple dimensión. Porque esas cosas de que hablamos son, en primer lugar, dos cosas: la universal y la singular en que aquélla se concreta, pero, además, cada una existe porque en su cuenca, por pequeña que sea, se encierra el resplandor de una idea modelo, de una idea arquetipo, de la que el objeto recibe su justificación y su destino. En esta forma, pasamos de lo individual a lo general, de lo concreto a lo esencial, pero en el salto que damos hacia la universalidad, nos hallamos remitidos a 
una forma divina, en que lo finito se disuelve en los deslindes de lo sobrenatural.

Menéndez y Pelayo nos ha hablado, según recordamos, de una recreación de la realidad por el artista, de una que él llama idealización de los objetos reales. El procedimiento por el cual se llega a este resultado es, también nos lo señala, el de la combinación de la intensidad con la extensión. Traduciendo dichas palabras a la psicología de la creación estética, tenemos entonces que el artista, lejos de copiar la realidad, la toma como un punto de partida, como un suelo en que debe apoyarse, para desde allí levantar el edificio de la creación. El procedimiento de intensidad consiste en penetrar dentro de la cosa o el objeto, en desnudarlo o desvelarlo de las apariencias o singularizaciones que lo limitan y coartan. En la realidad no hay sólo una superficie, una exterioridad con que entramos en tangencial y fortuito contacto. Para que la comprendamos y percibamos en todo su volumen y su ser, es indispensable que descendamos dentro de ella y nos deslicemos en su intimidad. Sólo así la tensión interna en que se hallará el artista, corresponderá a una entrada en lo interior de la cosa, a una compenetración con ésta. Los objetos no adquieren categoría estética en cuanto referencias o exterioridades con que nos relacionamos. En este último sentido son simplemente entidades utilizables, que se aprovechan o usan en cuanto medio para fines distintos de ellos. El paisaje por el cual cruzamos, tomado como camino que debe llevarnos más rápida o más lentamente hacia la meta a donde nos dirigimos, no tiene calidad propia, sino que se subsume en el punto de término al cual lo ligamos. Pero, si en determinado momento, descubrimos ese paisaje en su ser recóndito, esto es, lo desprendemos de toda relación que lo convierta en medio de algo que no es él, su fisonomía cambia y empieza a existir por sí mismo. Tal resultado sólo será posible de conseguir a través de lo que Menéndez y Pelayo llama procedimiento de in-tensidad, de penetración o interiorización en lo que cada ser tiene de insubstituible e irreemplazable. En el paisaje del ejemplo llegaremos a una penetración estética, en la medida en que lo consideremos como único y extraordinario, 
distinto de cualquier otro que hayamos contemplado o en cuyo deslinde nos sea dado ubicarnos. Por este procedimiento, los árboles, el cielo, el agua que componen paisaje semejante, pasan a ser algo recién visto, que surge súbitamente, como acabado de crear, ante nuestros ojos. La intensidad es, pues, una combinación de aislamiento y de exaltación de la realidad como entidad específica, que no se repite ni se vulgariza y que, por lo mismo, posee la virtud de evocarnos siempre lo que tiene de fresco y acabado de nacer, salido apenas de las manos que concluyen de crearlo.

La extensión, en cambio, complementa esta exaltación de la realidad como algo único e inédito, haciéndonos descubrir dentro de ella lo que posee de universal. Ya hemos visto que Menéndez y Pelayo subraya la creación artística como una idealización de lo real. Con esto quicre decir que la cosa percibida intensamente, revela que en su interior se aloja algo que la hacer ser lo que es y la vincula con una dimensión eterna. Esto que yo siento aquí, frente a mis pupilas, resonando en mi corazón, contiene mucho más que lo que su límite se revela capaz de indicar. A través del canal que la cosa es, extendiéndola como experiencia de una totalidad en que ella se integra, llego a darme cuenta de que esa cosa forma parte de un universo, participa de él, recibe y envía sus rayos en torno de todo lo que la circunda. La belleza que descubro y adivino me notifica de que la realidad portadora de ella posee ese atributo porque, además de ser algo único, distinto y singular, armoniza y se funde en su contorno universal, como la nota o el compás se disuelven en la sinfonía, no pudiendo existir ni ésta sin aquélla ni aquélla sin ésta.

De este modo, Menéndez y Pelayo se anticipa a muchas corrientes modernas, subrayando la independencia de la creación poética frente a la realidad externa de que surge. En tal sentido, lo creado por el artista es una nueva realidad, esta vez suya e interior, de la que ese artista es dueño omnímodo y total. Lo que el polígrafo santanderino llama "interpretación" es ese apoderamiento de lo real y su substitución por lo que el creador emite desde su intimidad. Y llega a tanto el afán categórico del crítico para subrayar y acentuar 
esta autonomía de la creación estética en frente de su objeto, que podemos decir que para él la realidad artística es una sobre-realidad, y el Licenciado Cabra, por alzarse por encima de los ejemplares de avaro que la vida puede mostrarnos, acusa una excelencia que no poseen ni el personaje de Plauto ni el personaje de Moliére. Prolonguemos un poco la base estética de Menéndez y Pelayo y tendremos los cimientos del suprarrealismo y de las más modernas formas de la autonomía interna del arte.

\section{III}

Recogiendo a través del análisis que llevamos hecho, los distintos elementos constitutivos de la posición estética y filosófica de Menéndez y Pelayo, nos encontramos con las líneas necesarias para configurar su concepto de la crítica literaria.

La crítica para él debe recorrer diversas etapas o estadios, hasta llegar al juzgamiento cabal y definitivo de la obra analizada.

En un primer estadio nos encontramos con la necesidad de reunir los hechos, de ceñirse a una información lo más numerosa, detallada y completa posible. Ya él mismo, en la adolescencia moceril, dirá en su programa para el estudio de la literatura española, que "para juzgar una obra es necesario estudiar los hechos, porque sin hechos no hay juicio". Esta actitud que podríamos filiar en cierto modo de positivista, toma del positivismo lo eficaz y necesario. No es posible penetrar en una obra o en un autor, si no comenzamos por definir y dibujar con la máxima claridad lo que ella y él son. La obra ha nacido en un determinado tiempo, pertenece a un instante histórico concreto, proviene de un hombre singular, que la escribió con tales fines y en tales condiciones. Para entrar en ella hay que entrar en todo lo que, con término orteguiano, deberíamos llamar su "circunstancia". El idealismo del crítico, tan evidente en su análisis de Pereda y en sus juicios sobre Pérez Galdós, como en otros escritos, no es un idealismo vacío, juego mental que se pierde y se anula en sus propios laberintos. Parte de una realidad muy concreta 
y definida y se ciñe a ella con toda fidelidad y espíritu científico, para no perder un sólo carácter de ésta. Pero cuando ya la ha circunscrito y dominado, cuando tiene su perfil claramente descrito, entonces esboza un segundo movimiento.

El crítico se alejará de los hechos y de los datos, a fin de mirarlos con una pupila reflexiva, meditadora. En este sentido, Menéndez y Pelayo nos da un constante ejemplo de probidad y de independencia intelectual y estética. No dejará que ningún prejuicio, ni menos un examen superficial y ligero, deformen la visión que de la obra se construye. Lo que él busca es comprender, abrazar en toda su amplitud la creación ante la cual se encuentra. Descendiendo en ella y en sus más escondidos repliegues, a través de una "simpatía" vital y acogedora, intenta hacerse él mismo el autor, revivir sus emociones, adentrarse en el núcleo central de que la obra ha surgido proyectada y juzgarla con absoluta independencia de otro criterio que no sea el estético.

Se ha dicho a menudo que Menéndez y Pelayo era un hombre estrecho de criterio cuando se interponían sus convicciones religiosas y que cayó con frecuencia en la injusticia al examinar las obras de escritores que no pertenecían a su bando. Desde luego, es indispensable señalar que fué un crítico extraño a las capillas y a los círculos y que con la misma amplitud de criterio aplaudió a hombres de posiciones antagónicas a la suya como reprobó a otros de su propio sector.

Quien lea con desapasionamiento y rectitud sus numerosas páginas de crítica literaria y filosófica, deberá reconocer que en ellas impera el afán de "entender" y que el maestro podía haber repetido con pleno derecho la frase de Leonardo: dove si grida non e vera scicnza. Donde se grita o se injuria no hay verdadero espíritu de verdad. Gregorio Marañón ha recordado la figura de Menéndez y Pelayo, docta, sencilla y humana, en su tertulia santanderina y en los círculos de Madrid, y ha destacado su mente generosa y amplia, en la que no cabían exclusiones partidistas. Con la misma devoción con que fué amigo de Pereda, lo fué de Clarín y de Pérez Galdós, y si en alguna oportunidad atacó o criticó ideas y escritos de este último, lo hizo 
por diferencias elevadísimas en la manera de pensar. Prueba de ello está en que, cuando el gran don Benito ingresó a la Real Academia Española, el discurso de recepción de Menéndez y Pelayo abundó en un examen inteligentísimo y perspicaz de las novelas galdosianas, en que se acusan la frecuentación de esas obras, la participación íntima en el sustrato psicológico y estético que las inspiró, y el cuidado de alzar sus juicios sobre planos puramente estéticos, sin mezclar los religiosos. Allí encontramos, incluso, la declaración de que siempre fué admirador de la obra galdosiana y ni siquiera en las discrepancias confesionales halló óbice para estimularla, llegando hasta el punto de hacer afirmación explícita de que sus reservas respecto de la novela Gloria no podían tenerse como expresiones de un juicio estético, por cuanto se referían estrictamente a una materia religiosa y se contenían en un libro de esta misma específica índole.

Convencido de la independencia del arte respecto de la moral, es decir, de que el artífice se orienta hacia su creación llevado por el perfeccionamiento de la obra que produce y no por fines extraños, docentes o apologéticos, consigna en una de sus obras las siguientes frases: "Esto del arte por la moral, del arte por el bien, fórmulas son y tienen que ser una espada de dos filos, terrible en manos del fanatismo sectario". El fin inmediato, añade, de la obra de arte, "no es otro que la producción de la belleza, y con producirla se cumple". "Es verdad trivialísima, concluye, que los géneros puros y libres del arte valen más estéticamente que los géneros aplicados y mixtos; mucho más la poesía épica y dramática que la poesía didáctica; mucho más la poesía que la oratoria o la historia; mucho más la novela que nada enseña y recrea apaciblemente el ánimo, que la novela que tiene por objeto dar nociones de economía política, de física o de astronomía, o defender fastidiosamente tal o cual tesis moral, consiguiendo las más veces prevenir contra ella al lector..."

Recorridos los dos estadios precedentes, o sea, ubicada y perfilada la obra en sí misma y en la atmósfera vital que la da origen, y luego mirada con la visión libre del que intenta considerarla como un ser estético, Menéndez y Pelayo entra en un tercer punto de su 
tarea. Al juzgar la obra, con la cual ha tratado de compenetrarse, el crítico no pretende mirar sólo dentro de sí y ver qué reacciones ha experimentado ante el objeto que contempla. No es su propia respuesta cmocional o psicológica la que le interesa, sino que procura desentrañar dentro de ella los motivos que la causan, las calidades o virtudes que la generan y que se suponen subyacentes o explícitas en la obra examinada. Hay en esta actitud un profundo y ejemplar respeto por la razón, esto es, por la transparencia del espíritu que es capaz de identificarse con lo que contempla y tiene en frente, lo cual reviste una considerable importancia.

El hombre es razón y emoción, mirada que se derrama en torno suyo para volverse intencionalmente todo cuanto percibe y alcanza, pero también singularidad, concreción que siente el mundo en una forma individual y exclusiva. La razón nos universaliza y nos multiplica, nos enriquece por una participación indefinida que tomamos en el ser de los demás. En otras palabras, nos abre y nos proyecta en una perspectiva amplísima, de la cual no queda excluído nada de lo que existe. Gracias a la razón, entendiendo por tal el espíritu en cuanto puede asumir interiormente el ser de todas las cosas, desde el mineral hasta la divinidad, el hombre posee una virtualidad infinita. La emoción, en cambio, nos tiñe de una nota excluyente, nos hace ser éste y no aquél, el que siente y obra así y no de la otra manera. Por lo tanto, nos cierra y nos comprime, imprimiéndonos una seductora singularidad, pero aislándonos en cierto modo de lo que está más allá de nosotros.

Es evidente que en una experiencia estética, y en un juicio de la misma índole, ambas deben combinarse. La razón sin la emoción es como una ventana que cae en una habitación desierta: permite que el paisaje entre en la vivienda, pero no hay nadie que lo contemple o lo perciba. La emoción sin la razón es, a la inversa, como el mismo cuarto, habitado por un sujeto, pero sin ventana que dé al exterior. Es la síntesis de una y otra, fecundadas recíprocamente en una resonancia interminable, lo que sirve de base a la experiencia estética, pero en tal enlace es el espíritu el que debe dar la tónica para 
que la emoción entre en contacto con el objeto del cual debe recibir la impronta o la huella creadora.

En Menéndez y Pelayo encontramos realizada esta combinación. No era un crítico de ideas, en la acepción de un crítico imbuído de prejuicios de tesis inflexibles, pero era sí un crítico que tenía ideas y se alzaba sobre ellas para juzgar los engendros artísticos y ubicarlos en el orbe estético. Se daba plena cuenta de que había que vivir cultural y estéticamente desde una metafísica, y así lo sostenía a los veinte años y lo repetía en las lindes de su ocaso. "Sin metafísica, afirmaba, no se piensa ni siquiera para negar la metafísica”.

Ya hemos visto que para la visión platónica del maestro, el ideal era el sustrato de la realidad. Las cosas estaban hechas, como para el autor del Fedro, de unas ciertas esencias imperecederas, que en ellas se avistaban, y el papel del crítico, rastreador infatigable de despuntes divinos en el cañaveral de las cosas finitas, consistía en desprender de lo real ese como fulgor de ultramundo que contiene prisionero.

La forma artística era el instrumento o elemento que religaba en el objeto bello los dos orbes de lo real y de lo ideal, de lo singular y de lo universal. La cosa, interiorizada en el creador, hecha sangre de su propia sangre y devuelta después en el movimiento de la creación, fundía ambas categorías mediante la forma. Por consiguiente, esta última no era una simple exornación o adorno exterior del objeto, sino el punto o momento en que lo individual se convertía en algo abierto e infinito y el artista lograba engarzar y aprisionar, como en un solo resplandor, la idea ejemplar de que la realidad proviene y el vaso en que se vierte y se derrama para concretarse y hacerse perceptible.

Esta forma es la suprema ordenadora de los materiales, que pueden ser tomados de la realidad inmediata como de una realidad transmutada y alquitarada, distante infinitamente del mundo estrecho y fugaz que nos rodea. El artista coordina mediante ella el objeto artístico y nos lo pone a nuestro alcance, pero es faena del crítico redescubrir dicha forma para, partiendo de ella, descender hasta los 
materiales que ahora contempla trabados en la obra colocada a su vista.

Interesa señalar aquí, aunque sea de paso, que Menéndez y Pelayo no pudo llegar a esta conclusión sobre la crítica, ni a ser el crítico agudo y penetrante que fué, sino porque había dentro de él un poeta. Podrá negarse la calidad de su obra lírica directa y es seguro que a muchos de nosotros nada nos dirán las viejas estrofas, bebidas en los clásicos latinos y, sobre todo, en su dilecto Horacio. Es evidente que mucha de esa poesía nos huele a adocenada y acartonada, sin el vigor de una vivencia directa e impetuosa y también sin la artificiosa y delicada elaboración que el objeto poético requiere. Es decir, no hay en ella ni la experiencia avasalladora de una intuición que por sí misma nos arroja en una hondura entrañable ni la construcción estética de lo que podríamos llamar una poesía pura. Lo que indudablemente hallamos allí es la riqueza de una sensibilidad fina, penetrante, para la cual el mundo se desplegaba como una armonía y una musical secuencia de seres y cosas.

Ahora bien, es evidente que este poeta que había en Menéndez y Pelayo adolecía de una cierta incapacidad para crear directamente. Sus vivencias de lo real, es decir, del mundo, son débiles y apagadas. Sentimos la impresión de que el mundo no resuena en su alma con agudeza y violencia, sino amortiguado y como entrevisto a través de otros ojos, de otras imágenes. Examinando el problema más de cerca, nos encontramos con que Menéndez y Pelayo no era un poeta de la realidad sino un poeta de lo literario. Es decir, a poco que meditemos en el por qué de este fenómeno, descubrimos que era un poeta reflejo y en cierto modo irrealizado, que no se logró en la creación directa y propia sino en la reflexión de la poesía ajena.

El aserto se comprueba con la vida misma del escritor. Todos sabemos que era un hombre de capacidad extraordinaria para leer y asimilar. Desde su niñez su afán de saber y su deseo vehemente de conocerlo todo, alcanzaron dimensiones sorprendentes, descomunales. Se cuenta, desde luego, que siendo un niño de no más de ocho o diez años, unos amigos de sus padres lo llevaron a un espectáculo de 
feria en una ciudad veraniega donde pasaban una temporada. En ese espectáculo se presentaba una cabeza parlante, que respondía a las preguntas que el público quisiera hacerle y que se referían a determinado acaecer histórico. Lo cierto es que cuando el pequeño Marcelino se encontró frente a ella y comenzó a hacerle preguntas, la cabeza comenzó a perder la suya y a balbucir y enredarse, en forma de que muy pronto no pudo contestar a la verdadera ametralladora de interrogaciones precisas, categóricas y asediantes que le dirigían. Al final, el empresario optó por regalarle entradas para un circo vecino, con tal de que no siguiese agobiando al pobre infeliz que tras el mascarón se escondía. Este afán de saber no lo abandonó jamás, pero iba también acompañado de una exclusión de muchas otras cosas. Porque el amor a los libros redujo la vida de Menéndez y Pelayo prácticamente a ellos, es decir, al estudio, al pensamiento, a la meditación.

Es curioso en este sentido leer la correspondencia cambiada por él con Pereda durante el viaje a Italia del erudito santanderino. Apenas se habla en esas cartas de la ciudad, de sus calles, de sus habitantes o de sus costumbres. En cambio, en cada página nos encontramos con referencias a visitas a bibliotecas, a descubrimientos de códices desconocidos, a recuerdo de lecturas o a reviviscencia de escritores clásicos o modernos. Se ve que la realidad para Menéndez y Pelayo es siempre un tema literario o filosófico, y que la menor circunstancia, el más mínimo de los hechos, pone en marcha su prodigiosa erudición, su espantable memoria, para hacer acudir a su mente todo lo que sabe y conoce.

Lo mismo acontece cuando comparamos sus poesías con sus juicios sobre poetas. La creación directa, la vivencia personal, se acusa en las primeras débil y atenuada, aunque siempre fina y armoniosa. En cambio, cuando ya no está ante la realidad desnuda, inmediata, sino ante la que exhibe y recoge otro escritor, la vena artística y lírica de don Marcelino surge desembarazada y libre, espigando aquí y allá intuiciones deslumbrantes, recorriendo el cuerpo de la 
novela, del poema o de la evocación histórica, con un vigor, una seguridad y una elegancia que desconciertan.

Es el poeta reflejo que puede expresarse a través de la poesía de los demás y que, aún cuando crea la suya con ligero desmayo, sabe percibir con penetración y vigor la que resplandece en las obras que examina.

Cuando miramos a la altura de nuestro tiempo el legado de Menéndez y Pelayo, no es posible desconocer su importancia considerable y la anticipación que representa de la investigación literaria moderna. Es preciso pensar que, cuando surge en las letras españolas, esa investigación es apenas el esfuerzo de uno que otro solitario, como su maestro Milá y Fontanals. Menéndez y Pelayo la organiza y traza la ruta, creando un precedente que aún hoy día irradia su lección. Del positivismo toma el método experimental, basado en la observación de los datos, en la acumulación de todos los antecedentes que permitan filiar la obra, ubicarla, trazar sus límites históricos y hacerla susceptible de un examen científico. Pero, aunque su época esté inficionada de positivismo y sólo exhiba como vaga contrapartida un krausismo amorfo y vacilante, no se queda en el mero positivismo, sino que anticipa intuiciones que sólo muchos años más tarde tendrán vigencia.

Una de esas intuiciones es su sentido historicista, su comprensión de que cada obra nace dentro de un tiempo y se proyecta desde él, siendo indispensable para comprenderla el sumergirse en su atmósfera histórica y revivirla desde ella. Con justificado motivo Lain Entralgo ha encontrado coincidencias sorprendentes entre el punto de vista de Menéndez y Pelayo y muchas de las posiciones del filósofo Guillermo Dilthey.

Otra consiste en el afán de penetrar en la obra, abandonando las limitaciones y los lastres de un prejuicio individual, de una posición meramente subjetiva que alce vallados insalvables entre el objeto que contempla y la mirada del contemplador. Su ademán es el de quien deja a un lado todo cuanto aleja y distancia, por excesiva acentuación de las actitudes emocionales, para abandonarse y entregarse a 
una penetración amorosa, esto es, hecha de simpatía con la situación y con la obra de que ésta emerge. En tal sentido, su propósito de penetrar en la obra y de reconstituir lo más certeramente posible los materiales psicológicos, morales y estéticos que la constituyen, lo hace un precursor de las corrientes estilísticas contemporáneas, que sin el supuesto de la actitud de Menéndez y Pelayo, seguida por su discípulo Menéndez Pidal y la larga secuela que lo continúa, hoy no serían posibles.

Finalmente, debe subrayarse su resuelto afán de juzgar las obras literarias bajo especie de belleza, sin sujeción a cánones extraños a las categorías estéticas, pero aplicando a ellas un principio rector, un núcleo conceptual, que ubica la creación no sólo en su momento y en su circunstancia, sino en un plano universal de valores, a la luz de los cuales se juzga y examina.

Partiendo de que la realidad tiene como substrato una Idea, y de que el papel del artífice y, por lo tanto, del crítico, es desentrañar el significado de lo real mediante la desvelación de esa Idea, Menéndez y Pelayo convierte al arte en un intermediario humano entre el orden absoluto y el caos que nos envuelve. Los seres se ordenan a medida que reflejan la gran armonía de lo trascendental, porque hay como un musical movimiento que los hace partir y, luego, los devuelve a las esferas divinas. La cosa solitaria, finita, nace de una creación infinita, que deposita en ella su impronta. El artista, rasgando el velo de lo concreto, debe redescubrir ese depósito y, a través de él, llegarse hasta lo eterno e ilimitado. La armonía del arte es una especie de música de las esferas donde el hombre puede volver a escuchar, y hasta repetir en vacilante balbuceo, la belleza insondable que alcanzó fugazmente a entrever. 